\title{
Perceived Stress as a Predisposing Factor in Suicidality among Adolescents
}

\author{
R.N. Singh ${ }^{1}$, Neha Pathak ${ }^{2}$ \\ ${ }^{1}$ Professor of Psychology, Banaras Hindu University, Varanasi (India). \\ ${ }^{2}$ Research Scholar in Psychology, University of Magadh, Bodh-Gaya (Bihar).
}

Corresponding Author: R.N. Singh

Email-singhrnbhu@gmail.com

\begin{abstract}
Background and Objectives: This paper deals with the suicidality among adolescents in relation to perceived stress in life. It has been estimated that over one million people kill themselves in our country and suicidality is one of the important psychological variables leading to suicidal deaths and the younger generation happens to be a very vulnerable group to suicide.

Methods: It was hypothesized that higher the perceived stress by the participants, higher the suicidal tendency among the adolescents and vice-versa. In all, 290 randomly selected adolescents (Male= 140; Female $=150)$ of higher secondary classes participated in this study. They were administered the Global Perceived Stress Scale (Singh \& Pathak, 2016) and the TS Suicidal Ideation scale (2004).

Results: The descriptive and inferential statistics were used to analyze the data. It was found that perceived stress is a potential cause of suicidality

Conclusion: The results suggest that the higher the level of perceived stress, higher the chances of indulging in suicidal thoughts. The proposed hypotheses were approved. The results are thoroughly discussed and interpreted and the implications of the finding are properly underlined. Besides, limitations and suggestions of the present study are also indicated.
\end{abstract}

Keywords: Global perceived stress, HSG, MSG, LSG, Suicidality, Adolescents.

(Paper received $-2^{\text {nd }}$ May 2018, Peer review completed $-3^{\text {rd }}$ June 2018)

(Accepted - 12 ${ }^{\text {th }}$ June 2018)

\section{INTRODUCTION}

Suicide is a serious health problem for the person concerned as well as the related families and the country. According to estimates, over one lac people kill themselves in India every year [1-2]. Suicide can be considered as a silent enemy of the people. There is a common public misperception that only those who are diagnosed with depression are at risk of committing suicide or being in the grip of suicidality. However, almost $40 \%$ of the people who commit complete suicide are not clinically depressed; this indicates that various other psychological conditions could also potentially increase the risk of suicide and suicidality.

\section{Stress}

Stress is a term often used synonymously with negative life experiences, or life events [3]. The long persistence of an overloading condition, in this case, stress, ultimately leads to mental health disturbances or the appearance of disease [4]. The increasing pace of life, rushed and competitive lifestyles mean that stress is an integral part of human life. A person in a state of adapting to stress shows behavioural defenses. This leads to changes in one's cognitive processes and emotional landscape. 
The diathesis-stress model suggests that people have in different degrees, predispositions for developing depressive symptoms [5]. Such vulnerabilities are referred to as diatheses. People having more of these diatheses are more likely to develop depressive symptoms than other people. The impact of particular stressors varies across different people. The "fight or flight" model, describes how animals and people react to stress or danger (McCann). He noted that a sequence of actions occurs in the nerves and glands, preparing the body to defend and fight, or escape to a safe place [6].

\section{Suicidality}

Suicidality refers to the thoughts in the minds of people that life isn't worth living. It is also known as suicidal ideation. It may range in intensity from fleeting thoughts to plans for killing oneself, or a complete preoccupation with self-destruction or self-harm. It is characterized as a personality disorder or with the character of emotional blackmail [7]. It is one of the dimensions of suicidal behaviour which includes suicidal ideation, suicide planning, and suicide attempt that may lead to suicide. It is a useful indicator of identifying the people being at risk for suicide [8].

\section{Background}

The factors assumed to be associated with suicidal behaviour and deaths may be conceptualized as the risk or vulnerable factors and resiliency or protective factors. There may be some precipitating factors also. According to Gutierrez and Osman, the risk factors may be classified into individual risk factors and family risk factors, and protective factors into personal protective factors and environmental protective factors [9]. Besides, the psychological factors also play a very important role in understanding the psychological wellbeing of those who have the potential to be involved in suicide and suicidal ideation [10]. A deeper understanding of such factors would be highly helpful in dealing with this epidemic [11-13].

Rosiek and others [14] found that chronic exposure to stressful conditions may lead to psychological discomfort, mental health problems, depression and anxiety symptoms which might increase risk for suicidal thinking. We should be aware of the need to combat stress and suicidal thinking and of the fact that it can protect us against the development of illnesses such as depression, and other psychological problems. Negative occupational and academic events also increase risk for suicidal behaviour and suicidal thinking, so it is important to know how people can be trained to cope with stress [15-16]. It has been reported that coping plays a central role in dealing with stressors of life [10].

Ibrahim, Amit and Suen [17] examined psychological factors (i.e., depression, anxiety and stress) as predictors for suicidal ideation among Malaysian adolescents. The results show that $11.10 \%, 10.00 \%$, and $9.50 \%$ of the students reported that they were experiencing severe depression, anxiety and stress, respectively. There were significant correlations between depression, anxiety, and stress with suicidal ideation. However, only depression was identified as a predictor for suicidal ideation.

In some other studies also, stress was found to be positively associated with suicidal ideation [18-19]. There are various work-and-life related stressors, such as stressful life events, loss, unemployment, and other environmental stressors, which could be associated with suicidal ideation [11, 20]. The interactions of various aspects of stressors have the potential to make stress management difficult and have the potential to lead to suicidal ideation [21]. Therefore, stress management requires the integration of a good quality of life, coping skills, and problem-solving skills. The way people cope with stress may indicate the extent to which stress may affect their psychological well-being, how far stress may lead them to feeling a sense of hopelessness or of not being supported, and how they may define stress as a potential contributor to suicidality.

\section{Present study}

As the review shows, researchers in general are of the view that stress and suicidal behaviour are considerably related and in many cases, stress requires attention of health experts and care givers [12-13, 22]. Like depression and anxiety and other mental health problems, stress is also a contributor to suicidal ideation among people in general and the adolescents in particular. In the case of experiencing negative events, stress and suicidal behaviour may be triggered. It, therefore, becomes imperative to identify the factors which contribute to suicidal behaviour and develop the programmes for enhancing resilience among people to cope 
with the negative experiences in life and ensuring their well-being. In our country, there is a dearth of researches on suicidality and suicide. The reason behind it may be, among other factors, the taboo about suicide. In our country, like many other countries, suicide is treated as an undesirable behaviour and people often avoid talking about suicide and suicidality.

Objective: To examine the stress and its effects on suicidality among adolescents

Hypotheses: Keeping in view the studies conducted in this area and the objective of the present study, following hypotheses were framed for empirical examination.

H1. High and moderate stress groups of adolescents would differ significantly in suicidality.

H2. High and low stress groups of adolescents would differ significantly in suicidality

H3. Moderate and low stress groups of adolescents would differ significantly in suicidality

\section{METHODOLOGY}

\section{Sample}

290 adolescents $($ Male $=140$; Female $=150)$ enrolled in higher secondary schools of Jaunpur district (U.P., India) were randomly selected for testing. Their age ranged between 12 and 19 years, with mean age being 14.85 years. They were divided into high stress group (HSG; $N=86$ ), moderate stress group (MSG; $N=145$ ) and low stress group (LSG; N=119) on the basis of their scores on Global Perceived Stress Scale (GPSS).

\section{Design}

The present study tapped perceived stress as the independent variable and the suicidality was measured as the dependent variable. The stress was measured in terms of high, moderate and low stress levels.

\section{Tools}

\section{Global Perceived Stress Scale (GPSS)}

The Hindi version of perceived stress scale by Cohen, Kamarck and Mermelstein [23], adapted by Singh and Pathak [24], was used to assess the degree to which situations in one's life are viewed as being stressful. It is a Likert type scale having 14 - items with 5 alternative responses $(0=$ never; $1=$ almost never; $2=$ sometimes; $3=$ fairly often; $4=$ very often). PSS scores are obtained by reversing the scores on the seven positive items, e.g., $0=4,1=3,2=2$, etc., and then summing across all 14 items. Items 4, 5, 6, 7, 9, 10, and 13 are the positively stated items. The scores on different items are averaged for the total score which may be between 0 and 56, with higher scores indicating greater levels of perceived stress. Internal consistency of the GPSS was found to be .79 and it suggests a high level of internal consistency about the Hindi version of GPPS.

\section{T-S Suicidal Ideation Scale}

This scale has been developed by Singh and Thakur [25]. This is a Likert type scale and measures suicidal tendency among respondents. This scale consists of 20 items accompanied by 5 alternative responses. Its reliability by odd-even method is 0.78 and by spilt-half method is 0.82 , whereas the validity is 0.78 . Higher scores on it indicate greater tendency of suicidal ideation and vice -versa.

\section{Procedure}

All the participants were seated comfortably and the procedure of responding to the items was properly explained to them. The participants were clearly told about the task they had to do and good rapport was established before starting the testing. They were taken in full confidence that their responses are being taken for research purpose only and will be kept fully confidential. The scale was collected from them after getting their responses and they were thankfully relieved from the testing.

\section{RESULTS}

The results obtained in the present study are recorded in tables 1,2 and 3. A perusal of table 1 makes it obvious that the group of adolescents scoring high on stress scale (HSG) has also scored higher mean (40.25) than the other two groups (MSG= 36.40; LSG= 29.82). It suggests that stress is an important predictor of 
suicidality among adolescents. It interferes with the coping skills and thus may instigate the adolescents to opt the extreme step like committing suicide. The higher the level of stress, higher the probability on the part of the person concerned to indulge in suicidal thoughts.

Table-1: Descriptive statistics for three stress groups on Suicidal Ideation Scale

\begin{tabular}{|l|l|l|l|l|}
\hline Levels of stress & $\mathrm{N}$ & Mean & S.D. & SEm \\
\hline High stress group (HSG) & 56 & 40.25 & 6.39 & 0.12 \\
\hline Moderate stress group (MSG) & 164 & 36.41 & 5.92 & 0.04 \\
\hline Low stress group (LSG) & 70 & 29.82 & 5.73 & 0.08 \\
\hline
\end{tabular}

The significance of difference in suicidality among the three stress groups was examined by computing $\mathrm{F}$ ratio. Table 2 shows that $\mathrm{F}$-ratio $(\mathrm{F}=8.35$ is significant at .01 level. This suggests that the difference between the three groups is real, not attributable to chance variable. In other words, stress has been found to exert differential effects on suicidality among adolescent participants.

Table-2: Summary of ANOVA among three stress groups on Suicidal Ideation scale

\begin{tabular}{|l|l|l|l|l|}
\hline Source of variation & Df & Sum of squire & Mean squire & $\mathrm{F}$ \\
\hline Between groups & 2 & 1976.62 & 988.31 & $8.35^{* *}$ \\
\hline Within groups & 287 & 34106.28 & 118.83 & \\
\hline Total & 289 & & & \\
\hline
\end{tabular}

Table 3: t-ratios for three stress groups on suicidality scale

\begin{tabular}{|l|l|l|l|}
\hline Stress Groups & df & t-ratio & P \\
\hline High vs Moderate & 218 & 4.43 & 0.01 \\
\hline High vs Low & 124 & 10.03 & 0.01 \\
\hline Moderate vs Low & 232 & 8.04 & 0.01 \\
\hline
\end{tabular}

The significance of difference, between the mean scores of three stress groups in suicidality, was further examined by computing $t$-ratios. Table 3 shows that the $t$-ratios obtained between HSG vs MSG $(t=4.43)$, HSG vs LSG $(t=10.03)$ and MSG vs LSG (8.04) are significant at 0.01 level. This very clearly suggests that perceived stress exerts differential effects on suicidality among the adolescents. The proposed hypotheses are, therefore, approved.

\section{DISCUSSION}

It was hypothesized that perceived stress would exert differential effects on suicidality among adolescents. The findings revealed that higher the level of stress, higher the probability of indulging in suicidal thoughts. This indicates that stress is a serious threat to the life and well-being of people in general and the adolescents in particular. The stress negatively influences their cognition, feeling and behaviour which may lead to serious problems such as depression and suicidal thinking. Many studies indicate that depressive symptoms beginning at an early age can have serious developmental and functional consequences, such as academic failure in future. Stress causes negative emotional states such as depressive symptoms, chronic stress, especially in young people, which are connected with susceptibility to alcohol addiction, drug abuse, crime, and a range of other adverse phenomena [26-29].

The findings of this study extend empirical support to Zhang and others [30] and Bender and others [31] who reported positive relationship between stress and suicidal ideation. In some other studies also stress and stressful life events were found to be strongly associated with increased risk of suicide [32-34]. Rosiek and 
others [14] also reported significant positive relationship between stress and suicide. Since stress is often considered as a negative experience, it may disrupt the normal functioning of the affected person and may ultimately cause the feeling of frustration, hopelessness and meaninglessness in life. Such feelings may induce suicidality, hence must be given due attention for preventing suicide and managing the suicidal thoughts [35].

In our country as also in many other developing countries, there is general dearth of studies on suicidality and the reason behind it is the taboo about suicide prevailing in the society even today. In our society suicide is tabooed and talking about it is not desirable, but because of the increase in suicide in India, now it has become a focal theme of discussion at various platforms. The rate of suicide is rising and thus causing concern for the families and the administration as well. There may be several causal factors of suicide and suicidality and such factors may be classified into family factors, personal factors, psychological factors and so on. The predictive factors of suicidality need to be identified to protect the precious life of our people not only for their own well-being but also for the well-being of family and society $[12,16]$. Stress causes emotional upheaval which can easily take the people in its grip in general and the adolescents in particular, as the adolescence is the age of stress and storm, which may be instrumental in predisposing the affected persons for suicidal actions. The psychological factors thus need to be given due attention for ensuring optimal well-being among our people and preventing suicides.

\section{CONCLUSION}

The results obtained in this study revealed that stress is a potential factor in determining and predicting the suicidality among the adolescents. The risk of suicidality and suicide increases with the increasing level of stress, i.e., higher the level of stress, greater the risk of indulging in suicidal thoughts by the affected persons. The findings also suggest that stress is an important psychological factor in suicidality and it must be taken seriously in developing any programme to control suicide and suicidality.

\section{Implications}

The findings of the present study make it obvious that suicidality is a major risk factor for our adolescents and psychological factors are more vital in predicting suicide and suicidality among them. The adolescent group seems to be more vulnerable to suicidal behaviour. It is felt that the adolescents be assessed and screened with suitable measures for counselling and enhancing their well-being. The affectionate social support and counselling for restructuring their cognitive thoughts are supposed to be of high instrumental value to control suicide and protect the precious life of our people in general and the adolescents in particular.

\section{Limitations and Suggestions}

This study was conducted on adolescents selected from a particular district of eastern U.P. and it limits the generalizability of the findings. So, selecting a sample representing broader geographic area is expected to provide more useful findings. Besides, the people from other age groups and belonging to varied locales should be covered for more generalizable results. It is also felt that other psychological factors (i.e., depression\& anxiety, life events), family and economic factors should also be tapped in future studies and correlational approach is expected to provide more intensive picture of the relationship between suicidality and its predictive factors.

\section{REFERENCES}

1. World Health Organisation. Statistics on suicide. WHO; 2012.

2. National Crime Bureau Record. Three hundred people killing themselves everyday in India. Tarun Mitra Hindi Daily, Jaunpur. 2000.

3. Selye H. A syndrome produced by diverse nocuous agents. Nature 1936;138(3479):32-8.

4. Lazarus RS. From psychological stress to the emotions: A history of changing outlooks. Ann Rev Psychol 1993;44(1):1-22.

5. Monroe SM, Simons AD. Diathesis-stress theories in the context of life stress research: implications for the depressive disorders. Psychol Bull 1991;110(3):406-20.

6. Zimbardo PG, Gerring RJ. Psychology and Life. Scientific. Publishers PWN; Warsaw, Poland. 2012. 
7. Abasse ML, Oliveira RC, Silva TC, Souza ER. Análise epidemiológica da morbimortalidade por suicídio entre adolescentes em Minas Gerais, Brasil. Ciência and Saúde Coletiva 2009;14:407-16.

8. Favazza AR. Why patients mutilate themselves. Psychiatr Serv 1989;40(2):137-45.

9. Gutierrez PM, Osman A. Adolescent suicide: An integrated approach to the assessment of risk and protective factors. Northern Illinois University Press; 2008.

10. Grygorczuk A. The Concept of Stress in Medicine and Psychology. Via Medica; Mentreal, QC, Canada. 2009;111-115.

11. Spirito A, Overholser JC. Evaluating and treating adolescent suicide attempters: from research to practice. Elsevier; 2003.

12. Singh RN, Pathak N. Gender Disparity in Suicidality: Myth or Reality. J Psychosoc Res 2017;12(2):48592.

13. Pathak N, Singh RN, Singh UP. Suicide and Suicidality in India: Vulnerabilities and Resiliency.

14. Rosiek A, Rosiek-Kryszewska A, Leksowski Ł, Leksowski K. Chronic stress and suicidal thinking among medical students. Int J Environ Res Pub Health 2016;13(2):212-8.

15. Arun P, Chavan B. Stress and suicidal ideas in adolescent students in Chandigarh. Ind J Med Sci 2009;63(7):281-8.

16. Liu X, Tein JY, Zhao Z, Sandler IN. Suicidality and correlates among rural adolescents of China. J Adolesc Health 2005;37(6):443-51.

17. Ibrahim N, Amit N, Suen MW. Psychological factors as predictors of suicidal ideation among adolescents in Malaysia. PLoS One. 2014 Oct 23;9(10):e110670.

18. Gould MS, Greenberg TE, Velting DM, Shaffer D. Youth suicide risk and preventive interventions: a review of the past 10 years. J Am Acad Child Adolesc Psychiatry 2003;42(4):386-405.

19. Singh R, Joshi HL. Suicidal ideation in relation to depression, life stress and personality among college students. J Indian Acad Appl Psychol 2008;34(2):259-65.

20. Singh R, Joshi HL. Suicidal ideation in relation to depression, life stress and personality among college students. J Indian Acad Appl Psychol 2008;34(2):259-65.

21. Foo XY, Alwi MN, Ismail SI, Ibrahim N, Osman ZJ. Religious commitment, attitudes toward suicide, and suicidal behaviors among college students of different ethnic and religious groups in Malaysia. J Religion Health 2014;53(3):731-46.

22. Wallace BE, Masiak J, Pabis MR. Depression in medical students: reviewing its prevalence, risk factors, consequences, and management in order to provide student treatment recommendations for the Polish medical education system. Polish J Pub Health 2013;123(3):1-6.

23. Cohen S, Kamarck T, Mermelstein R. A global measure of perceived stress. J Health Soc Behav 1983;12:385-96.

24. Singh RN \& Pathak N. Global Perceived Stress Scale (Hindi version). Department of Psychology, Banaras Hindu University, Varanasi (India). Prasad Psycho Corpn. Varanasi/ New Delhi. 2016.

25. Singh RN \& Thakur GP. TS Suicidal Ideation Scale. Prasad Psycho Corpn., Varanasi/ Delhi. 2004.

26. Cash SJ, Bridge JA. Epidemiology of youth suicide and suicidal behavior. Curr Opin Pediatr 2009;21(5):613-8.

27. Kessler RC, Avenevoli S, Merikangas KR. Mood disorders in children and adolescents: an epidemiologic perspective. Biological psychiatry. 2001 Jun 15;49(12):1002-14.

28. Rutter M, Kim- Cohen J, Maughan B. Continuities and discontinuities in psychopathology between childhood and adult life. J Child Psychol Psychiatry 2006;47(3- 4):276-95.

29. Makara-Studzinska M, Pylypczuk A, Urbanska A. Occurrence of depression and anxiety disorders according to the period of abstinence in patients addicted to gambling and alcohol. J Pre-Clin Clin Res 2011;5(1).

30. Zhang X, Wang H, Xia Y, Liu X, Jung E. Stress, coping and suicide ideation in Chinese college students. J Adolescence 2012;35(3):683-90.

31. Bender WN, Rosenkrans CB, Crane MK. Stress, depression, and suicide among students with learning disabilities: Assessing the risk. Learning Disabil Quart 1999;22(2):143-56.

32. O'Connor RC, Rasmussen S, Hawton K. Predicting depression, anxiety and self-harm in adolescents: The role of perfectionism and acute life stress. Behav Res Ther 2010;48(1):52-9.

33. Anestis MD, Soberay KA, Gutierrez PM, Hernández TD, Joiner TE. Reconsidering the link between impulsivity and suicidal behavior. Personal Soc Psychol Rev 2014;18(4):366-86.

34. You Z, Chen M, Yang S, Zhou Z, Qin P. Childhood adversity, recent life stressors and suicidal behavior in Chinese college students. PloS One 2014;9(3):e86672.

Acknowledgements - Nil; Conflict of Interest - Nil; Funding - Nil 